\title{
Alterations in Anatomy and Ultrastructure of Pecan Leaves Treated with Propiconazole during Shoot Expansion
}

\author{
Hazel Y. Wetzstein, ${ }^{1}$ Elizabeth A. Richardson, ${ }^{2}$ and Yi He \\ Department of Horticulture, University of Georgia, Athens, GA 30602
}

\begin{abstract}
AdDitional INDEX wORDs. Carya illinoinensis, cell arrangement, sterol biosynthesis inhibitor, transmission electron microscopy

Abstract. Propiconazole, a triazole fungicide, has been reported to inhibit leaf expansion in pecan [Carya illinoensis (Wangenh.) K. Koch] trees when applied under field conditions. This study was conducted to determine the effect of propiconazole on pecan leaf morphology and structure using light and transmission electron microscopy. Mature pecan trees were sprayed once or three times per week from budbreak to pollen maturity. Fungicide sprays resulted in significantly reduced leaf area. Compared to controls, leaves from propiconazole-treated shoots had alterations in cell arrangement characterized by more tightly packed palisade parenchyma cells with fewer intercellular spaces; neither leaf thickness nor palisade or spongy layer thickness were affected. Propiconazole caused modifications in the chloroplasts, with a tendency for internal membranes to be less defined, and for thylakiods to exhibit less stacking. The extent of structural changes was related to fungicide dosage. Results show that propiconazole applications during leaf development can inhibit leaf expansion and modify cellular organization of the mesophyll cells. Chemical name used: 1[[2-(2,4-dichlorophenyl)-4-propyl-1,3-dioxolan-2-yl] methyl]-1H- 1,2,4-triazole (propiconazole).
\end{abstract}

Proper timing and good coverage of fungicide applications are very important for successful pecan (Carya illinoensis) production (Ellis et al., 1997; Sparks, 1995). Current spray programs are designed to assure that a protective fungicide shield is consistently present, particularly during the early season to protect rapidly developing young foliage (Ellis et al., 1997; Graves and Diehl, 1991). Recently, climatically-based fungicide applications have been proposed (Sparks, 1995) and are used frequently. However, calendar-based procedures are still in use, with sprays scheduled every 10 to $14 \mathrm{~d}$ from budbreak through pollination (Ellis et al., 1997). Under extremely wet weather conditions, intervals between sprays may be shorter.

Propiconazole belongs to the group of triazole derivatives related to sterol biosynthesis inhibitors (Steffens, 1988), and is one of the primary early season fungicides used in pecan (Ellis et al., 1997; Reilly and Wood, 1996). These compounds bind to the cytochrome $\mathrm{P} 450$ component of the $\mathrm{C}-14$ demethylase and inhibit $14 \alpha$-methylation, and thus function as fungicides (Coolbaugh and Hamilton, 1976; Coolbaugh et al., 1978; Worthington, 1989) and/or plant growth regulators (Buchenauer and Röhner, 1981; Burden et al., 1987; Köller, 1987) primarily by reducing gibberellin biosynthesis.

Uniconazole [(E)-1(p-chlorophenyl)-4,4-dimethyl-2-(1,2,4triazol-1-yl)-1-penten-3-ol] and paclobutrazol [(2RS,3RS)-1-(4chlorophenyl)-4-4-dimethyl-2-(1H-1,2,4-triazol-1-yl) pentan-3ol] are triazole compounds that are used widely in horticulture as growth retardants. The morphological and cytological effects of these growth inhibitors have been documented in a number of crops and include suppressing shoot elongation and limiting the rate of leaf production (Wang and Gregg, 1989, 1994; Wang et al. 1992). Uniconazole applications in hibiscus (Hibiscus rosasinensis L.) resulted in shorter pedicels with larger pith, vascular, and cortical tissue (Wang and Dunlap, 1994). Paclobutrazol

Received for publication 12 June 2000. Accepted for publication 11 Sept. 2001. 'Corresponding author; e-mail: hywetz@arches.uga.edu.

${ }^{2}$ Department of Botany. application resulted in thicker leaves and reduced stem diameter in 'Lillian Hoek' chrysanthemum [Dendranthema $\times$ grandiflora (Ramat.) Kitam. (syn. Chrysanthemum Xmorifolium Ramat.)] (Burrows et al., 1992), and decreased leaf length in wheat (Triticum aestivum L.) as a result of cell length reduction (Tonkinson et al. 1995).

Applications of triazole fungicides have exhibited adverse effects on various higher plants. In apple [Malus sylvestris (L.) Mill var. domestica (Borkh.) Mansf. 'Cox's Orange Pippin'], decreased tree growth (Church et al., 1984; Steffens, 1988), decreased ovule longevity, and reduced ovary size (Williams et al., 1987) were observed. Reilly and Wood (1996) found that propiconazole sprays suppressed leaf expansion in young pecan seedlings, and reported a progressive decline in leaf area as dosage increased. In our previous studies with pecan (He and Wetzstein, 1994), propiconazole applied during shoot development limited shoot growth, leaf expansion, catkin elongation, and pollen development. Nonetheless, the cytological events associated with the inhibitory effects of propiconazole on leaf growth have not been ascertained. In the present study, we describe differences in the anatomy and ultrastructure of pecan leaves following propiconazole applications under field conditions.

\section{Materials and Methods}

PLANT MATERIaL AND FIELD APPLICATIONS AND MEASUREMENTS. Mature, 'Desirable' pecan trees, located at the University of Georgia Horticulture Farm near Watkinsville, Ga., were used for this investigation. Terminal shoots used in the study were selected at budbreak for uniformity (i.e., from the outer portion of the canopy, with a caliper of $\approx 1 \mathrm{~cm}$, and a length of 25 to $35 \mathrm{~cm}$ ). Five shoots were randomly assigned per treatment. Leaves and shoots were sprayed with propiconazole, in the form of Orbit (CibaGeigy, Greensboro, N.C.) at the recommended rate of $0.3 \mathrm{~mL} \cdot \mathrm{L}^{-}$ ${ }^{1}$ in water ( $0.125 \mathrm{mg} \cdot \mathrm{L}^{-1}$ of propiconazole), either once or three times weekly. Control shoots were sprayed with water. Sprays were applied with a hand-held spray bottle until runoff. Applications were from budbreak to pollen maturity, a period of $\approx 1$ 
Table 1. Influence of propiconazole sprays on pecan leaf area and anatomy. ${ }^{\mathrm{z}}$

\begin{tabular}{lcccc}
\hline \hline $\begin{array}{l}\text { Propiconazole } \\
\text { treatment }\end{array}$ & $\begin{array}{c}\text { Leaf area } \\
\left(\mathrm{cm}^{2}\right)\end{array}$ & $\begin{array}{c}\text { Leaf cross-sectional } \\
\text { thickness }(\mu \mathrm{m})\end{array}$ & $\begin{array}{c}\text { Palisade layer } \\
\text { thickness }(\mu \mathrm{m})\end{array}$ & $\begin{array}{c}\text { Spongy layer } \\
\text { thickness }(\mu \mathrm{m})\end{array}$ \\
\hline Water control & $221.5 \mathrm{c}^{\mathrm{y}}$ & $171.4 \mathrm{a}$ & $58.6 \mathrm{a}$ & $87.9 \mathrm{a}$ \\
$1 \times$ weekly & $120.2 \mathrm{~b}$ & $181.4 \mathrm{a}$ & $62.9 \mathrm{a}$ & $93.5 \mathrm{a}$ \\
$3 \times$ weekly & $98.8 \mathrm{a}$ & $171.4 \mathrm{a}$ & $63.6 \mathrm{a}$ & $85.7 \mathrm{a}$
\end{tabular}

${ }^{\mathrm{z}}$ Propiconazole was applied at the rate of $0.125 \mathrm{mg} \cdot \mathrm{L}^{-1}$. Anatomical measurements were taken from photographs of leaf sections in regions devoid of vascular bundles, statoliths, and trichomes.

yMean separation $(\mathrm{n}=5)$ within columns by Duncan's multiple range test, $P<0.05$.

${ }^{\mathrm{x}}$ Number of palisade cells per $100 \mu \mathrm{m}$ cross-sectional length.

month. The experiment was repeated a second year on different trees in the same orchard to confirm anatomical observations.

LEAF AREA AND SHOOT LENGTH MEASUREMENTS. Current season's shoots were harvested after leaf expansion had ceased. Leaf area measurements were taken using a leaf area meter (LI-3000; LICOR, Lincoln, Nebr.).

PREPARATION OF LEAF SAMPLES FOR MICROSCOPY. For anatomical and ultrastructural evaluations, tissues were sampled from leaves located midway along the shoot, after leaf expansion had ceased. Leaves in pecan are pinnately compound. A leaflet from the midportion of the leaf was selected, and tissue samples were obtained

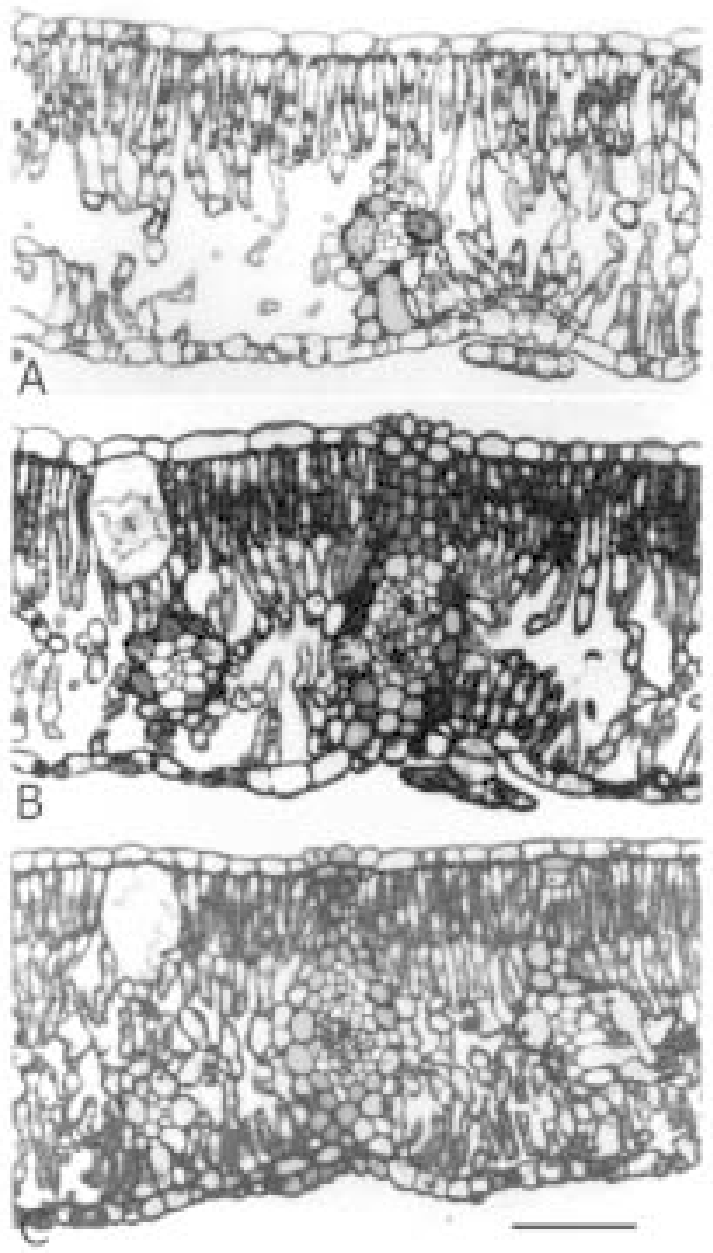

Fig. 1. Light micrographs of transverse sections of leaves from control and propiconazole-treated shoots of pecan. (A) Leaf from water-sprayed control shoot, (B) leaf from shoot treated once a week with propiconazole, and (C) leaf from shoot treated three times a week with propiconazole. Scale bar in $(C)=50$ $\mu \mathrm{m}$ and applies to all figures. from the central region of the blade adjacent to the main veins of the leaflet. Tissues were prepared for light (LM) and transmission electron microscopy (TEM) as described previously for pecan leaves (Wetzstein and Sparks, 1983). Briefly, samples were fixed in $2 \%$ glutaraldehyde in $0.1 \mathrm{M}$ cacodylate buffer ( $\mathrm{pH} 7.2$ ), postfixed with $1 \%$ osmium tetroxide in the same buffer, and dehydrated in a graded ethanol series. The samples were infiltrated and embedded in Spurr's (1969) low viscosity resin (EM Sciences, Fort Washington, Pa.).

For LM, $1-\mu \mathrm{m}$-thick sections were cut with an ultramicrotome (MT6000-XL; RMC, Inc., Tucson, Ariz.) and collected on glass microscope slides coated with gelatin and chrome-alum. Sections were stained with $1 \%$ pergamon solution (Fisher Scientific, Inc., Springfield, N.J.), and mounted in a medium containing glycerol and Tris- $\mathrm{HCl}$ (He et al., 1995). The slides were examined with a microscope (Axioscop; Carl Zeiss, Thornwood, N.Y.) equipped for differential interference contrast. Leaf thickness, heights of palisade and spongy mesophyll regions, and number of palisade cells along the leaf sections were measured. Ten different leaf samples were evaluated per treatment, and mean values per leaf were obtained from measurements of five different microscopic fields.

For TEM, thin sections ( $\approx 80 \mathrm{~nm})$ were obtained also using an ultramicrotome, and collected on Formvar-coated, gilded copper slot grids (Ted Pella, Redding, Calif.) and placed on Formvarcoated bridges to dry. The sections were poststained with $4 \%$ (w/ v) aqueous uranyl acetate and Reynolds (1963) lead citrate. Sections were examined with a transmission electron microscope (Zeiss EM 902A; LEO Electron Microscopy, Thornwood, N.Y.) at $80 \mathrm{kV}$.

Statistical analyses. Numerical data were subjected to analysis of variance procedures and means separated by Duncan's multiple range test using general linear model procedures of SAS for personal computers (SAS Inst., Inc., 1990). For leaf area, data were transformed with natural logarithms.

\section{Results}

Effects of propiconazole on shoot growth were apparent within 2 weeks after initial sprays, and persisted in affected shoots. Shoots treated with propiconazole were substantially shorter (data not presented), and leaf expansion was severely reduced (Table 1). The mean area of leaves sprayed weekly with propiconazole during expansion was only $54 \%$ of water controls. The inhibition symptoms were more severe in shoots treated more frequently. Leaves sprayed three times per week had a leaf area that was only $48 \%$ of control leaves.

Propiconazole also altered leaf anatomy. The cellular organization of control leaves exhibited typical features of pecan leaves (Fig. 1A). The upper and lower epidermis were uniseriate and 
frequently had peltate, glandular trichomes that were more numerous on the abaxial or lower surface. The mesophyll was differentiated into a palisade and spongy parenchyma with dominant intercellular spaces, especially in the spongy region. Leaves treated with propiconazole exhibited marked differences which were more extensive with the higher spray frequency (Fig. 1B and C). The mesophyll of leaves treated with propiconazole was composed of more closely packed cells and had fewer intercellular spaces, and the number of palisade cells per $100-\mu \mathrm{m}$ crosssectional length was significantly greater (Table 1). Leaves sprayed at the higher frequency had $1.3 \times$ more palisade cells than controls. Neither total leaf thickness nor thickness of spongy and palisade cell layers were significantly affected by sprays.

Electron micrographs of mesophyll tissues from control (Fig. 2A) and propiconazole- sprayed leaves (Fig. 2B and C) illustrate differences in palisade cell organization. In control leaves, the palisade cells were aligned primarily in a single layer with cells of variable lengths interspersed with intercellular spaces. Cells had large vacuoles. More internal cells (from the adaxial surface) were elongated, but loosely packed. Palisade cells from leaves sprayed with propiconazole were more uniformly columnar in shape and length, and were more closer packed (Fig. 2B and C). Leaves sprayed at the higher frequency had two distinct, compactly arranged palisade layers with few intercellular spaces (Fig. 2C). Palisade cells had less vacuolar space, that was frequently composed of numerous vacuoles.

Control leaves had well defined membrane structures (Fig. 3A and B). The double membrane structure of the nuclear envelope was clearly evident. Chloroplasts generally had well defined thylakoid membranes organized into granal stacks of varying heights. In leaves treated weekly with propiconazole, starch grains were more numerous within the chloroplasts (Fig. 3C and D). Although some chloroplasts exhibited structural characteristics similar to the control, there was a tendency for internal membranes to be less defined. Thylakoids showed less stacking and the stroma often stained more densely than controls. Leaves treated three times per week with propiconizole had a greater incidence of membrane perturbations (Fig. 3E and F). Thylakoid membranes were less organized and indistinct. Starch grains were observed frequently. In some cases, the chloroplast stroma was amorphous with few membrane profiles observed. Occasionally, nuclear membranes were more sinuous and irregularly spaced.

\section{Discussion}

Although the inhibitory effects of triazoles on leaf expansion have been documented, their possible anatomical manifestations have received little attention. Burrows et al. (1992) evaluated leaf structure in chrysanthemum leaves treated with a paclobutrazol soil drench. Leaves had an additional layer of palisade mesophyll, although the individual palisade cells were shorter, and more tightly packed. Benton and Cobb (1995) reported epoxiconazole (a triazole used as a fungicide) caused elongated palisade and spongy mesophyll, as well as upper epidermal cells in cleavers (Galium aparine L). The triazoles, triadimefon and S-3307, applied as seed treatments increased epicuticular wax and reduced the length but increased the width and thickness of wheat leaves (Gao et al., 1988). In the current study, the palisade cells of the leaves from the propiconazole-treated shoots were similarly more densely packed with less intercellular spaces than the controls. The palisade mesophyll was composed of more cell layers, with cells more elongated and better defined.
Reports on the effects of triazoles on leaf thickness have been mixed. Burrows et al. (1992) demonstrated that paclobutrazol increased leaf thickness of 'Lillian Hoek' chrysanthemum. Benton and Cobb (1995) showed that epoxiconazole caused increase of leaflet thickness of cleavers. In contrast, Thetford et al. (1995) reported that uniconazole treatments of 'Spectabilis' forsythia

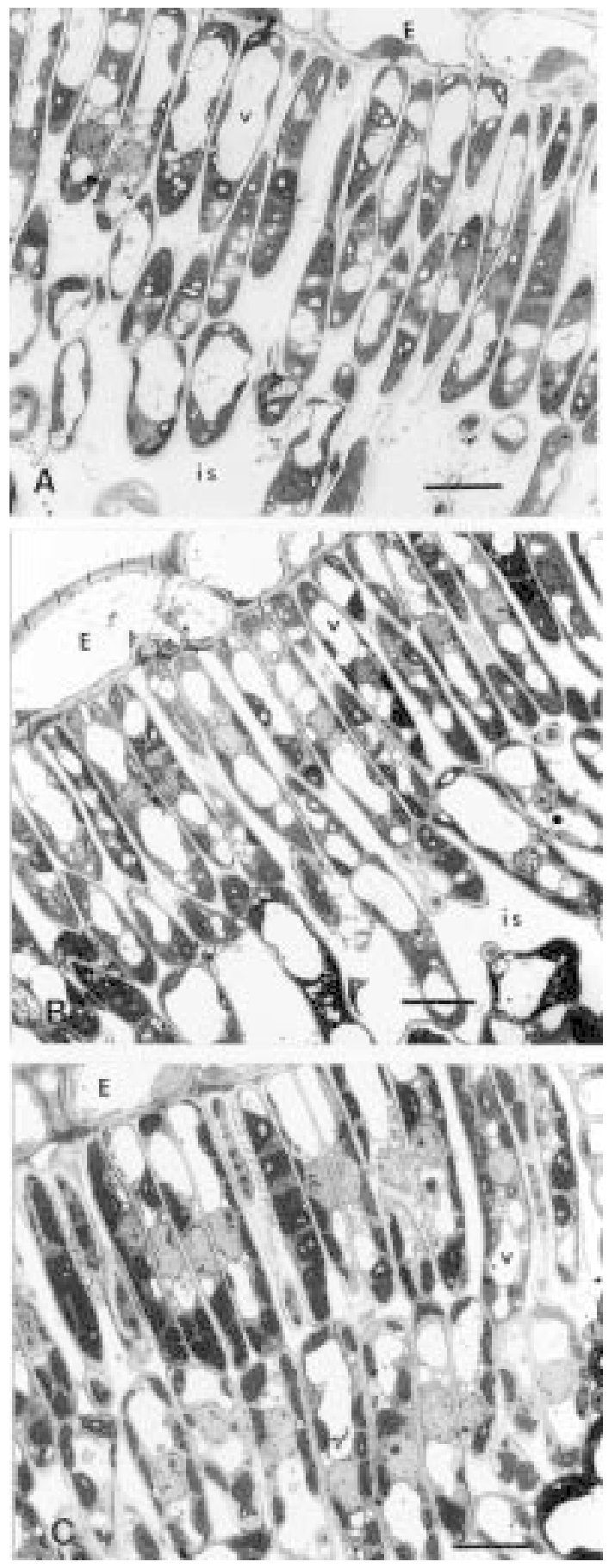

Fig. 2. Transmission electron micrographs of the palisade mesophyll of pecan leaves. (A) Section from a control leaf showing vacuolate palisade cells with intercellular spaces. (B) Section from a leaf sprayed once per week with propiconazole. The palisade cells are more columnar and closely packed. (C) Tissue from a leaf sprayed three times per week with propiconazole. The palisade is composed of two distinct layers of compactly arranged cells. Palisade cells have fewer intercellular spaces. $\mathrm{E}=$ epidermal cell, is = intercellular space, and $\mathrm{v}=$ vacuole. Scale bars $=10 \mu \mathrm{m}$. 
(Forsythia $\times$ intermedia Zab.) had no effect on leaf thickness. Likewise, propiconazole did not affect pecan leaf thickness in the current study. Wang and Gregg (1989) demonstrated uniconazole restricted cell division and differentiation in treated hibiscus. Differences in response may reflect the time of application and/ or genetic differences in patterns of cell elongation and division in leaves. For example, spray applications made after completion

Fig. 3. Transmission electron micrographs of pecan leaf sections. (A) Watersprayed control leaf. Chloroplast has well-defined granal stacks. The double membrane structure of the nucleus is clearly evident. (B) Higher magnification of control leaf. (C, D) Leaf sections from shoots sprayed once-a-week with propiconazole. The chloroplast has starch grains and grana which are less stacked than in controls. (E, F) Leaves from shoots sprayed three times per week with propiconazole. Chloroplast membranes are less distinct with little stacking of thylakoids. $\mathrm{CW}=$ cell wall, $\mathrm{M}=$ mitochondrion, $\mathrm{Nu}=$ nucleus, $\mathrm{S}=$ starch. In $\mathrm{A}, \mathrm{C}$, and $\mathrm{E}$ scale bars $=1 \mu \mathrm{m}$ and in $\mathrm{B}, \mathrm{D}$, and F scale bars $=5 \mu \mathrm{m}$. of marginal meristem activity would be anticipated to have less impact on the number of cell layers comprising the palisade and spongy mesophyll than earlier sprays.

It is reported that leaves from triazole-treated plants contain higher chlorophyll concentrations or an alteration of chlorophyll synthesis (Benton and Cobb, 1995; Thetford et al., 1995; Wang and Gregg, 1989), thus resulting in a greening effect. In the current study, no apparent increase in the number of chloroplasts in individual mesophyll cells was evident with propiconazole treatments. However, the number of mesophyll cells per unit leaf area increased due mainly to a closer cell arrangement. Benton and Cobb (1995) also found that epoxiconazole-treated leaflets of cleavers had more palisade and spongy cells per unit area with fewer air spaces. They proposed that the tightly packed cells might be due to inhibition of cell separation caused by epoxiconazole. Thus, relatively few extracellular spaces and vacuolar areas may contribute to the observed greener leaves.

Triazoles may restrict plant growth by inhibition of phytosterol biosynthesis (Burden et al., 1987; Köller, 1987). Buchenauer and Röhner (1981) suggested that the growth-retarding activity of triadimefon and triadimenol, two triazole fungicides, was the result of inhibition of both gibberellin and sterol biosynthesis. By simultaneous application of gibberellic acid $\left(\mathrm{GA}_{3}\right)$ with epoxiconazole on cleavers, Benton and Cobb (1995) indicated that the inhibitory effect of epoxiconazole on stem elongation could be counteracted by $\mathrm{GA}_{3}$. Such inhibition of both gibberellin and sterol biosynthesis can result in accumulation of sterol precursors, possibly altering membrane integrity and functioning (Steffens, 1988). In the present study, chloroplast in leaves sprayed with propiconazole had thylakoid membranes with less stacking and internal membranes that were less defined. Modifications in membrane structure have likewise been reported with other triazole compounds. Paclobutrazol treatments in maize (Zea mays L.) seedlings increased the abundance of stroma lamellae and reduced the number of grana stacks in mesophyll chloroplasts (Sopher et al., 1999). Pring (1986) found that triadimefon applied to wheat seedlings caused fragmentation of the tonoplast and plasmalemma, and disintegration of chloroplasts. However, effects were localized and limited to cells adjacent to stomata which they attribute to accumulation and movement of the chemical in the transpi- 
ration stream. In studies with corn and soybean [Glycine max (L.) Merrill] seedlings (Barnes et al., 1989), paclobutrazol and uniconazol had no visible effect on chloroplast ultrastructure, in contrast to amitrol-t, which caused serious disruption of chloroplast membrane structure as well as a reduction of grana and stroma thylakoids.

Triazole fungicides are used widely in many agricultural and horticultural crops. While these fungicides have contributed greatly to control a variety of plant diseases, considerations should be made on their affects on plant development. In the present study, a triazole compound, propiconazole, applied to pecan leaves inhibited leaf expansion, altered mesophyll cell arrangement, and affected integrity of chloroplast membranes. The extent that these cytological changes may have on plant production warrant further investigation.

\section{Literature Cited}

Barnes, A.M., R.H. Walser, and T.D. Davis. 1989. Anatomy of Zea mays and Glycine max seedlings treated with triazole plant growth regulators. Biologia Plant. 31:370-375.

Benton, J.M. and A.H. Cobb. 1995. The plant growth regulator activity of the fungicide, epoxiconazole, on Galium aparine L. (cleavers). Plant Growth Regulat. 17:149-155.

Buchenauer, H. andE. Röhner. 1981. Effect of triadimefon and triadimenol on growth of various plant species as well as on gibberellin content and sterol metabolism in shoots of barley seedlings. Pest. Biochem. Physiol. 15:58-70.

Burden, R.S., G.A. Carter, T. Clark, D.T. Cooke, S.J. Croker, A.H.B. Deas, P. Hedden, C.S. James, and J.R. Lenton. 1987. Comparative activity of the enantiomers of triadimentol and paclobutrazol as inhibitors of fungal growth and plant sterol and gibberellin biosynthesis. Pest. Sci. 21:253-267.

Burrows, G.E., T.S. Boag, and W.P. Stewart. 1992. Changes in leaf, stem, and root anatomy of Chrysanthemum cv. Lillian Hoek following paclobutrazol application. J. Plant Growth Regulat. 11:189-194.

Church, R.M., L. Copas, and R.R. Williams. 1984. Changes in fruit size, leaf size and shoot growth of apple caused by some fungicides, insecticides and a plant growth regulator. J. Hort. Sci. 59:161-164.

Coolbaugh, R.C. and R.R. Hamilton. 1976. Inhibition of ent-kaurene oxidation and growth by $\alpha$-cyclopropyl- $\alpha$-(p-methoxyphenyl)-5-pyrimidine methyl alcohol. Plant Physiol. 57:245-248.

Coolbaugh, R.C., S.S. Hirano, and C. West. 1978. Studies on the specificity and site of action of $\alpha$-cyclopropyl- $\alpha$-[p-methoxyphenyl]5-pyrimidine methyl alcohol (ancymidol), a plant growth regulator. Plant Physiol. 62:571-576.

Ellis, H.C., P. Bertrand, T.F. Crocker, and G. MacDonald. 1997. Georgia pecan pest management guide. Ga. Coop. Ext. Serv. Bul. 841.

Gao, J, G. Hofstra, and R.A. Fletcher. 1988. Anatomical changes induced by triazoles in wheat seedlings. Can J. Bot. 66:1178-1185.

Graves, Jr., C.H. and S.V. Diehl. 1991. Prospects for pecan disease management and needs in disease management research for the immediate future. Proc. S.E. Pecan Growers Assn. 84:70-76.
He, Y. and H.Y. Wetzstein. 1994. Pollen degeneration and retarded leaf development from fungicidal sprays applied during microspore development and shoot expansion. J. Hort. Sci. 69:975-983.

Köller, W. 1987. Isomers of sterol biosynthesis inhibitors: Fungicidal effects and plant growth regulator activities. Pest. Sci. 18:129-147.

Pring, R.J. 1986. Ultrastructural changes occurring in wheat leaves following triadimefon treatment. Pest. Sci. 17:327-334.

Reilly, C.C. and B.W. Wood. 1996. No adverse effect of early season fungicide and zinc sprays on leaf area, fruit size, and nut quality of pecan. HortScience 31:808-810.

Reynolds, E.S. 1963. The use of lead citrate in high $\mathrm{pH}$ as an electronopaque stain in electron microscopy. J. Cell. Biol. 17:108-212.

SAS Institute, Inc. 1990. SAS personal computers release 6.03 ed. SAS Inst., Inc., Cary, N.C.

Sopher, C.R., M. Krol, N.P.A. Huner, A.E. Moore, and R.A. Fletcher. 1999. Chloroplastic changes associated with paclobutrazol-induced stress protection in maize seedlings. Can. J. Bot. 77:279-290.

Sparks, D. 1995. A climatic approach to pecan scab control. HortTechnology 5:225-230.

Spurr, A.R. 1969. A low-viscosity epoxy resin embedding medium for electron microscopy. J. Ultrastruct. Res. 26:31-43.

Steffens, G.L. 1988. Gibberellin biosynthesis inhibitors: Comparing growth-retarding effectiveness on apple. J. Plant Growth Regulat. 7:27-36.

Thetford, M., S.L. Warren, F.A. Blazich, and J.F. Thomas. 1995. Response of Forsythia xintermedia 'Spectabilis' to uniconazole. II. Leaf and stem anatomy, chlorophyll, and photosynthesis. J. Amer. Soc. Hort. Sci. 120:983-988.

Tonkinson, C.L., R.F. Lyndon, G.M. Arnold, and J.R. Lenton. 1995. Effect of the Rht 3 dwarfing gene on dynamics of cell extension in wheat leaves, and its modification by gibberellic acid and paclobutrazol. J. Expt. Bot. 46:1085-1092.

Wang, Y.-T. and J.R. Dunlap. 1994. Effect of $\mathrm{GA}_{4+7}$ on growth and cellular change in uniconazole-treated hibiscus. J. Plant Growth Regulat.13:33-38.

Wang, Y.-T. and L.L. Gregg. 1989. Uniconazole affects vegetative growth, flowering, and stem anatomy of hibiscus. J. Amer. Soc. Hort. Sci. 114:927-932.

Wang, Y.-T. and L.L. Gregg. 1994. Chemical regulators affect growth, postproduction performance, and propagation of golden pothos. HortScience 29:183-185.

Wang, Y.-T., K.-H. Hsiao, and L.L. Gregg. 1992. Antitranspirant, water stress, and growth retardant regulate growth of golden pothos. HortScience 27:222-225.

Wetzstein, H.Y. and D. Sparks. 1983. Anatomical indices of cultivar and age-related scab resistance and susceptibility in pecan leaves. J. Amer. Soc. Hort. Sci. 108:210-218.

Williams, R.R., D.V. Child, L. Copas, and M.E. Holgate. 1987. The mechanism of yield suppression by a triadimefon fungicide program on the apple cv. Cox's Orange Pippin. J. Hort. Sci. 62:291-294.

Worthington, P.A. 1989. Chemistry of sterol biosynthesis inhibitors: Piperazines, pyridines, pyrimidines, imidazoles, 1,2,4-triazoles, morpholines, piperidines, allylamines, p. 19-55. In: B. Berg and M. Plempel (eds.). Sterol biosynthesis inhibitors pharmaceutical and agrochemical aspects. Ellis Horwood, Chichester, United Kingdom. 